\title{
Treatments of a phthalocyanine-based green ink for tattoo removal purposes: generation of toxic fragments and potentially harmful morphologies
}

\author{
Elvira Maria Bauer ${ }^{1} \cdot$ Emanuele Vincenzo Scibetta $^{2} \cdot$ Daniele Cecchetti $^{2} \cdot$ Susanna Piccirillo ${ }^{2} \cdot$ Simonetta Antonaroli $^{2}$. \\ Simona Sennato ${ }^{3,4} \cdot$ Marina Cerasa $^{5} \cdot$ Pietro Tagliatesta $^{2} \cdot$ Marilena Carbone $^{2}(1)$
}

Received: 12 May 2020 / Accepted: 20 May 2020

(c) Springer-Verlag GmbH Germany, part of Springer Nature 2020

\begin{abstract}
Since tattoos became overwhelmingly fashionable worldwide, the demand for removal has proportionally increased, Nd:YAG Q-switch laser being the most commonly used tool for the purpose. In this framework we investigated the composition and products of laser treatment of green tattoo ink, the Green Concentrate from Eternal. The ink characterization has been carried out by IR, UV-Vis, EDX spectroscopies, and SEM imaging. It revealed the presence of the pigment PG7, rather than PG36 as reported on the bottle label, along with non-fully halogenated analogues. The morphology is an extended sheath with embedded grains. Subsequent laser treatments were performed on both dried and extracted inks, dispersed either in water or in propan-2-ol, chosen for their different polarities, as it is the case in the skin layers. The products were analyzed by gas chromatography-mass spectrometry, UV-Vis spectroscopy, SEM imaging, and dynamic light scattering. The outcome is a complex fragmentation pattern that depends both on the solvent and on the initial aggregation state. The fragment compounds are toxic at various degrees according to the Classification Labelling and Packaging regulations. Several shapes of aggregates are produced as an effect of both downsizing and re-aggregation, with potentially harmful aspect ratios.
\end{abstract}

Keywords Ink composition · Tattoo removal · Nd:YAG laser · Toxic fragments · Harmful morphology

\section{Introduction}

Electronic supplementary material The online version of this article (https://doi.org/10.1007/s00204-020-02790-7) contains supplementary material, which is available to authorized users.

Marilena Carbone

carbone@uniroma2.it; marilena.carbone@roma2.infn.it

1 Institute of Structure of Matter, (CNR-ISM), Italian National Research Council, Via Salaria km 23.9, 00015 Monterotondo, RM, Italy

2 Department of Chemical Science and Technologies, University of Rome Tor Vergata, Via della Ricerca Scientifica 1, 00133 Rome, Italy

3 Institute for Complex Systems (ISC), National Research Council (CNR), Rome, Italy

4 Physics Department, Sapienza University of Rome, P.le A. Moro 2, 00185 Rome, Italy

5 Institute for Atmospheric Pollution Research (CNR-IIA), Italian National Research Council, Via Salaria km 23.9, 00015 Monterotondo, RM, Italy
Since losing their maverick image, tattoos are no longer fringe groups markings, but a widespread practice with an estimated 120 million people tattooed worldwide (Everts 2016) in 2016. Fatally, tattoo regrets come along with the permanent marking procedures. Recent statistics indicate that a significant part of the tattooed population is having second thoughts, the number of remorseful people ranging from $17 \%$ up to $50 \%$ depending on the sampled population (Laux et al. 2016; Klitzman 2013). Reasons for regretting may be merely esthetical, related to a different outcome upon execution than planned, purely practical, when seeking a profession where tattoos are forbidden, medical, due to allergic reactions to one or more components of the tattoo inks, or may simply recall an unpleasant memory. Statistical analyses are being made on- the type of regretted tattoos as well as size, content, typical body spots, and how long it took before having afterthoughts (Statistics, https ://www.advdermatology.com/blog/statistics-surroundin g-tattoo-regret). Since most of the regretted tattoos was the 
result of impulsive action or were made under alcohol of recreational drug influence (Laumann and Derick 2006), the natural conclusion would be to "think-before-you-ink". Once it has been decided a tattoo needs removal, methods for deletion may be mechanical, when employing wire brushes, diamond coated fraises, sandpapers (dermabrasion), or abrasive salts (salabration) (Bernstein 2017). By now, the most commonly used method of tattoos removal is laser treatment, typically by Q-switched Nd:YAG which appears to be effective, because of the selective photothermolysis of the chromophores. The efficacy also depends on the chromophore size, it is a function of the pulse duration (Anderson and Parrish 1983) and works through a photoacoustic mechanism (Ara et al. 1990; Taylor et al. 1991). Addressing tattoos with lasers usually carries an unknown, because the composition of the earliest inks on the market did not need to be declared, and in many countries, it is still the case. In countries where regulations were enforced on tattoo inks labeling (Code of Federal Regulations 2015; ResAP 2008; TätoV 2008; Swiss Regulation 2005), systematic violations and false declarations (Bauer et al. 2019; Hauri 2014) jeopardize suited laser treatments.

However, even when the composition of the inks is known, there are inherent risks related to the generation of potentially harmful fragments, both from the pigment and the vehicle (i.e. the two components of a tattoo ink). In this regard, red pigments were primarily investigated as removal targets since they tend to be the most allergenic (Gaudron et al. 2014; Kaur et al. 2009). The cleavage of monoazo red pigments PR22 (C.I. 12315) and PR9 (C.I. 12460) upon irradiation with Nd:YAG laser yielded potentially hazardous 2-methyl-5-nitroaniline, 4-nitro-toluene, 2, 5-dichloroaniline and 1, 4-dichlorobenzene (Vasold et al. 2004). A systematic study on decomposition products of red pigments was performed by Hauri and Hohl (2015), by comparing sunlight and (a non-specified) laser treatment. In some cases, 2-amino-4-nitrotoluene, 3,3-dichlorobenzidine, and $o$-toluidine were identified as laser decomposition products. The $\mathrm{Nd}$ :YAG laser irradiation of pigskin tattooed post-mortem produced the toxic hexachlorobenzene when marked with the yellow chinophthalone PY138 (C.I. 56,300) and phenyl isocyanate, benzene, aniline, 3,3'-dichlorobenzidine, when marked with the orange diazo-pigment PO13 (C.I. 21110) (Hering et al. 2018). 1,2-benzene dicarbonitrile, benzonitrile, benzene, and hydrogen cyanide were produced by ruby laser irradiation of the blue pigment PB15:3 (C.I.74,160) (Schreiver et al. 2015).

When dealing with risks associated to the laser treatment of tattoo inks, a second aspect tends to be underestimated, i.e. the generation of particles potentially harmful by size and shape (Golka et al. 2004; Kluger and Koljonen 2012; Ma et al. 2017; Trouiller et al. 2009; Pan et al. 2009). Inks tend to aggregate as nanoparticles of different sizes as pointed out in a survey of 58 inks of by Høgsberg et al. (2011) who analyzed the average size as a function of the colors. In Bocca et al. (2017), analyzed 9 inks of different colors and found a large size polydispersion, with particles continuously distributed from tens to hundreds of nanometers. $\mathrm{TiO}_{2}$ nanoparticles in the $20-30 \mathrm{~nm}$ range were found in a green ink, with the white pigment as a lightening agent (Bauer et al. 2019). As for the fate of the inks nanoparticles and aggregates upon laser treatments, to date, we found only one paper reporting ink re-aggregation and ejection at high speed (Murphy 2018), which is of potential harm to personnel removing the tattoos and may have consequences for the treated person. On the other hand, it is important to gather information on morphological changes of treated inks, since they are likely part of the removal process. The discoloration of the tattooed skin is a complex process, which partially occurs at the very moment of the treatment, and mostly goes on afterward, to the level that it is usually recommended to take 6 to 8 weeks between laser removal sessions (Pothiawala et al. 2014). This hints at a double removal mechanism: from one side the molecular fragmentation of the pigment with immediate discoloration, on the other side the morphological and size changes of the ink allowing the intervention of macrophages in the removal, though in longer time scales. In either case, the products of laser treatment are potentially harmful.

In this overall scenario, we investigated the effects of a Nd:YAG laser irradiation of the Green Concentrate by Eternal Ink, Inc, i.e. a green phthalocyanine-based ink. We targeted this ink because green is one of the most difficult colors to be removed by laser (Ho and Goh 2015), and among green inks on the market, the Green Concentrate is one of the few reportedly containing one pigment only. Furthermore, we took into account that, though the ink mainly deposits in the dermis, different polarities characterized the skin layers as well as different areas in the same layer (Muroyama and Lechler 2012; Lu et al. 2018). To tackle the issue of generation of harmful components we performed Nd:YAG laser treatment of the ink dispersion in water and propane-2-ol, the second-largest component of the ink vehicle, and solvent of a different polarity than water. Furthermore, we proceeded with the pigment extraction form the ink, as for a mimicking a possible stripping of the vehicle from the pigment under the skin, and for gathering information by comparison with the ink. Also in this case we performed laser treatments of the dispersions in the two solvents.

The decomposition products were analyzed by gas chromatography/mass spectrometry, UV-Vis spectroscopy, scanning electron microscopy (SEM), and dynamic light scattering (DLS) to determine the fragmentation pattern, size, and shape of the particles upon irradiation. Prior to the laser treatments, the ink was subjected to UV-Vis and 
IR investigations, in comparison with pigments PG7 and PG36 to assess the correspondence between the label and pigment content. We found that the ink contains PG7, rather than PG36, as reported on the ink bottle. The morphology of the ink is a sort of extended sheath with embedded grains. Upon laser treatment a complex envelops of toxic fragments is produced which depends both on the solvent and on the initial aggregation. The size and shape of the particles are an effect of downsizing and re-aggregation with various shapes and potentially harmful aspect ratios.

\section{Materials and instruments}

The ink Green Concentrate by the brand Eternal Ink, Inc. was purchased in a regular tattoo shop located in Rome (Italy). The pigment PG36 was purchased from Schminke Künstlerfarben, PG7 from Kremer Pigmente GmbH from a local store specialized in raw materials for Arts \& Conservation. All chemicals used in this investigation were of reagent grade and used without any further purification. Sulfuric acid and acetone were purchased from Carlo Erba. Ethanol, propane-2-ol, DMSO, and ethyl acetate were received from Merck. All solutions were prepared with deionized water. The UV-Vis spectra were recorded with a Perkin Elmer, Lambda 950 spectrophotometer. Infrared spectra were recorded with a Shimadzu Prestige-21 FT-IR instrument, equipped with an attenuated total reflectance (ATR) diamond crystal (Specac Golden Gate), in the range $400-4000 \mathrm{~cm}^{-1}$, with a resolution of $4 \mathrm{~cm}^{-1}$. The laser treatments were performed with a Nd:YAG laser by Quanta System, operated at $532 \mathrm{~nm}$. GC-MS analysis was carried out using a Shimadzu GCMS QP2010 Ultra equipped with a AOi20 autosampler unit. A SLB®-5 ms capillary GC column $(\mathrm{L} \times$ I.D. $30 \mathrm{~m} \times 0.32 \mathrm{~mm}, d f=0.50 \mu \mathrm{m})$ was used as the stationary phase and ultrapure helium $(100 \mathrm{kPa}$ pressure) as the mobile phase. GC/MS peak identification was conducted using the open-source Openchrom software (Wenig and Odermatt 2010). Scanning electron micrographs (SEMs) were collected with a Zeiss Auriga Field EmissionScanning Electron Microscope instrument operating at $7 \mathrm{kV}$. The EDX analyses were made by coupling the Field Emission Scanning Electron Microscope (SUPRA ${ }^{\mathrm{TM}}$ 35, Carl Zeiss SMT, Oberkochen, Germany) with the Energy Dispersive Microanalysis (EDS/EDX, INCAx-sight, Model: 7426, Oxford Instruments, Abingdon, Oxfordshire, UK), operating at $20 \mathrm{kV}$. Prior to taking SEM images, dried and extracted inks were diluted in ethanol in a proportion 1:20 and sonicated at $59 \mathrm{kHz}$ for $1 \mathrm{~h}$. Then, they were deposited onto a Si wafer used as a sample holder and dried in air. For morphology and size distribution purposes, SEM images were taken of drops of inks dispersions upon 120 min laser irradiation, after deposition on Si wafers. Dynamic Light
Scattering (DLS) was used to determine the size and size distribution of ink and extracted in water and propan-2-ol after 120 min laser treatment. A Malvern NanoZetaSizer apparatus equipped with a $5 \mathrm{~mW}$ HeNe laser was employed (Malvern Instruments LTD, UK). Temperature is controlled by a Peltier system and it was fixed at $298 \mathrm{~K}$. The instrument uses a backscatter detection, i.e. the scattered light is collected at an angle of $173^{\circ}$, which is less sensitive to multiple scattering effects and dust than the $90^{\circ}$ geometry. In DLS the autocorrelation function of scattered intensity as a function of the decay times is analysed to obtain the distribution of the diffusion coefficients $D$ of the particles, which in turn are converted in a distribution of apparent hydrodynamic radii $R_{\mathrm{H}}$ using the Stokes-Einstein relationship $R_{\mathrm{H}}=k_{\mathrm{B}} T / 6 \Pi \eta D$, where $k_{\mathrm{B}} T$ is the thermal energy and $\eta$ the solvent viscosity (Berne and Pecora 2000).

As a preliminary analysis, the cumulant method has been considered to get the average hydrodynamic size $R_{\mathrm{H}}$ and the polydispersity index (PDI) (Koppel 1972). The intensityweighted $R_{\mathrm{H}}$ obtained by cumulant analysis is the most direct and robust measure of the size since it does not rely on the details of scattering. More, it is directly obtained from the initial part of the autocorrelation function where the signalto-noise ratio is largest. Unfortunately, $R_{\mathrm{H}}$ from cumulant analysis represents an average value over the whole sample and it may not be a significant representation when PDI values are larger than 0.2-0.3, where the size distribution could show more than one maximum. To ascertain this point, an intensity-weighted NNLS algorithm is used to determine the size and size distribution of the different objects eventually present in the dispersion (Lawson and Hanson 1974). Note that in the intensity-weighted analysis, being the scattered intensity proportional to the sixth power of the particle size, the obtained $\mathrm{R}_{\mathrm{H}}$ is biased on larger size.

\section{Methods}

A part of the ink has been subjected to vehicle stripping and freeing of the pigment by treatment with concentrated sulfuric acid and re-precipitation in water (Vicum et al. 2019). The sample obtained by extraction and re-precipitation was labeled E-GC (extracted Green Concentrate), whereas the dried ink was labeled D-GC (dried Green Concentrate). Treatments and subsequent analyses were carried out both on D-GC and E-GC, dispersed in solvents. The samples dispersed in distilled water were labeled $\mathrm{D}-\mathrm{GC} / \mathrm{H}_{2} \mathrm{O}$ and E- $\mathrm{GC} / \mathrm{H}_{2} \mathrm{O}$, those dispersed in propan-2-ol, D-GC/P2OL, and $\mathrm{E}-\mathrm{GC} / \mathrm{P} 2 \mathrm{OL}$.

The laser treatments were carried out by irradiating the samples with a power of $0.021 \mathrm{~J}$ over a surface of $0.04 \mathrm{~cm}^{2}$, (i.e. a fluence of $0.525 \mathrm{~J} \mathrm{~cm}^{-2}$ ). Typically, each sample was an $18 \mathrm{ml}$ dispersion of $9 \mathrm{mg} \mathrm{ml}^{-1}$ ink/dispersant. The 
dispersions do not need stirring during irradiation, due to the motion-triggered by the laser irradiation itself, thus guaranteeing a homogeneous treatment. The treatments were carried out until the initial hue of E-GC/P2OL faded, though did not discolor completely, which corresponds to a total irradiation time of $120 \mathrm{~min}$. Aliquots were sampled every 10 min treatment for GC-mass spectrometry, SEM analysis, and UV-Vis spectroscopy. All aqueous samples were extracted with ethyl acetate prior to GC-MS analysis.

Once the procedure was set for the first sample, the other ones were treated the same way. DLS measurements were carried out on the dispersion after 120 min laser irradiation.

\section{Results and discussion}

\section{Controversies on pigment content of green inks: PG36 and PG7}

The safety data sheet (SDS) of the Green concentrate by the Eternal reported PG36 as green pigment up to 2016 and PG7 from 2016 onwards. However, according to the label of the bottle we purchased, the ink still contains the pigment C.I. 74,265 , i.e. the PG36 (See Fig. SI1 of the Supplementary Information). The mismatch between SDS and label may be somewhat related to contradictory guidelines and legislations and the necessity of clear declarations of market products. Based on EU cosmetic regulation, the Council of Europe 2008 Resolution (ResAP 2008) on requirements and criteria for the safety of tattoos and permanent makeup highlighted PG7 among the pigments which should not be used in tattoo ink formulations due to its restriction in hair dye and eye products (ResAP 2008). This recommendation has been enforced into law, thus forbidding PG7 in

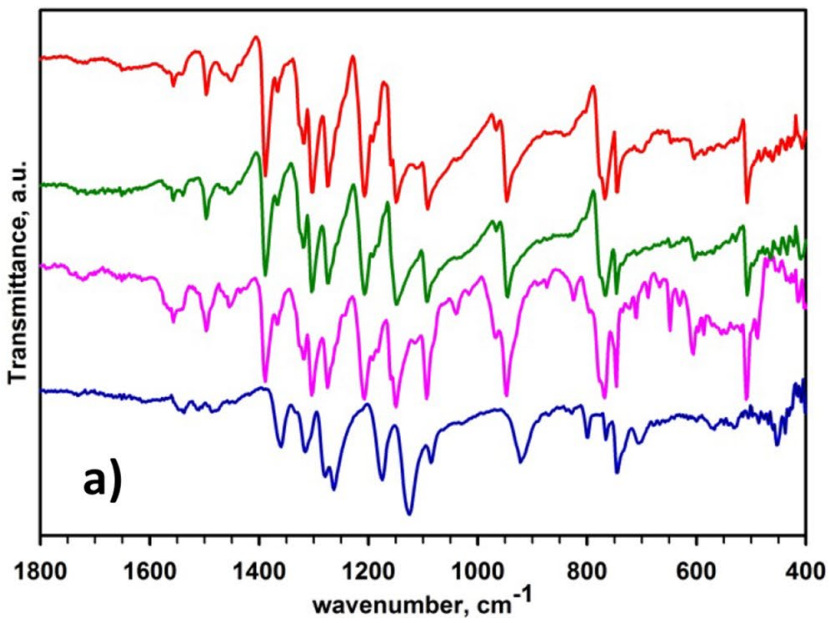

Fig. 1 a Infrared spectra and b UV-vis spectra of PG36 (blue solid line), PG7 (pink solid line), D-GC (green solid line) and E-GC(red solid line). The infrared spectra are taken on powder pigments or tattoo inks, earliest in Germany in 2008, with clarifications and corrections in 2016 (TätoV 2008), recently followed by Spain, France, Sweden, and the Netherlands (Regulations in single European countries). The national laws in force in Belgium and Norway are still based on the previous Council of Europe 2003 Resolution (ResAP 2003) but also in these countries PG7 has been excluded (ResAP 2003). The use of PG7 in tattoo inks is currently in a gray zone, as a derogation has been proposed by a 2016 REACH (Registration, Evaluation, Authorisation, and Restriction of Chemicals) regulation of the European Chemical Agency, based on deficiencies of the risk assessments (Compiled RAC and SEAC 2020). The proposal has been evaluated on Nov. 20, 2018 by the Committee for Risk Assessment (RAC), without providing conclusive indications (Compiled RAC and SEAC). On Nov. 29, 2018, the Committee for Socio-Economic Analysis (SEAC) assed that tattoo inks must be regulated by the REACH organism and, on the specific issue of PG7 use, supported "a 1 year transitional period as a reasonable timeframe for implementation" of the risk assessments (Compiled RAC and SEAC). According to the 2016 REACH proposal, PG36 might also enter a gray zone, since no specific use is indicated, thus leaving room for restrictive interpretation. Due to the mismatch between bottle label and recent SDS of the Green concentrate ink, we proceeded with IR, UV, and EDX analyses of ink and of the reference pigments PG36 and PG7, in order to assess the real content, prior to performing laser treatments.

\section{Ink characterization}

The assessment of pigment type in the Green concentrate ink was primarily made by comparative infrared spectra of inks D-GC, E-GC, and the pigments PG36 and PG7. The

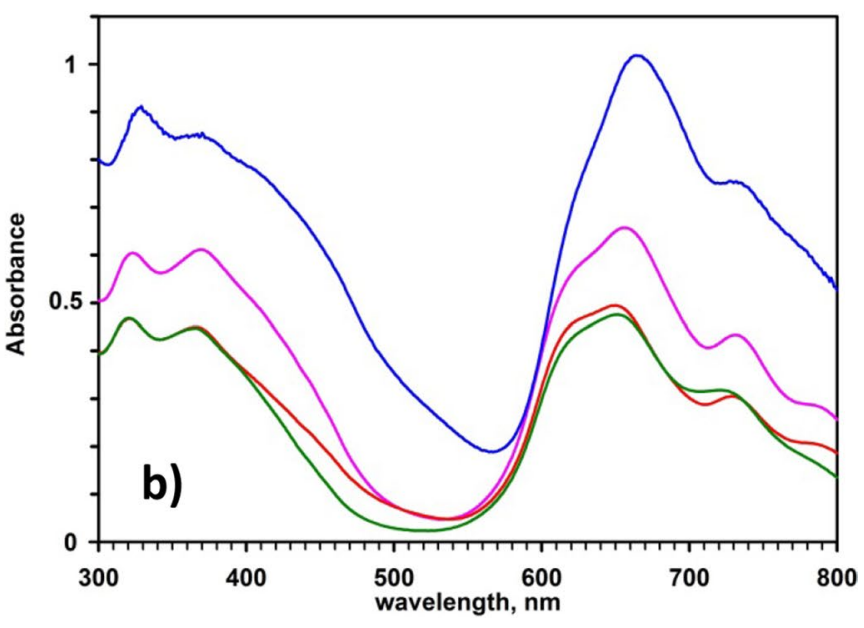

dried ink. The UV-vis spectra are recorded on dispersions in DMSO (color figure online) 
ensuing spectra are reported in Fig. 1a), whereas, the list of the peaks are reported in Table SI1 of the Supplementary Information. The features of PG36 and PG7 were previously analyzed (Bauer et al. 2019) and the assignments are briefly summarized here. The most significant bands and largest differences between the two pigments are in the region $1800-400 \mathrm{~cm}^{-1}$. In particular, PG7 only has appreciable peaks in the spectral region $1600-1500 \mathrm{~cm}^{-1}$, due to aromatic $\mathrm{C}=\mathrm{C}$ and $\mathrm{C}-\mathrm{N}$ stretching and $\mathrm{C}-\mathrm{N}-\mathrm{C}$ in-plane bending of the macrocyclic phthalocyanine ring. Bands characteristic of completely substituted copper phthalocyanine derivatives appear in the spectra of both pigments in the region between 1400 and $1000 \mathrm{~cm}^{-1}(\mathrm{C}-\mathrm{H}$ related features are missing, Barszcz et al. 2011). Almost all bands of PG7 in the region $1000-400 \mathrm{~cm}^{-1}$ are stronger as compared to PG36. The medium to strong broad absorptions around $750 \mathrm{~cm}^{-1}$, i.e. $777-768 \mathrm{~cm}^{-1}$ for PG7 and $775-765 \mathrm{~cm}^{-1}$ for PG36 are tentatively assigned to the $\mathrm{C}-\mathrm{Cl}$ stretching vibrations (Achar et al. 2007), whereas the broadening of the band around $745 \mathrm{~cm}^{-1}$ in the FT-IR spectrum of PG36 can be an effect of the $\mathrm{C}-\mathrm{Br}$ bonds (Venugopala Reddy and Keshavayya 2002). The subsequent comparison of D-GC and pigments spectra reveals a one-to-one correspondence between the ink and PG7 features, leaving no room for interpretation, and leading to the unequivocal assessment that the label reports a wrong indication. The only slight difference worth noticing is a lower intensity of the features in the range $5500-700 \mathrm{~cm}^{-1}$, for the D-GC as compared to PG7. In particular the PG7 stronger bands at $606 \mathrm{~cm}^{-1}$ and $648 \mathrm{~cm}^{-1}$ are still visible in D-GC, whereas the less intense ones at $667 \mathrm{~cm}^{-1}, 689 \mathrm{~cm}^{-1}$, and $710 \mathrm{~cm}^{-1}$ are concealed in the baseline. This small difference is not ascribable to PG36, because the relatively intense peak at $459 \mathrm{~cm}^{-1}$ is absent in the D-GC spectrum. A possible explanation may be a hampering effect of the vehicle. As it is shown in the SEM images of Fig. 2, the vehicle is a sort of sheath around the pigment and may have an effect on the vibrations of the phthalocyanine, with an impact more perceivable at lower energies. The infrared spectra of E-GC and D-GC are very similar, thus indicating that the extraction procedure did not alter the pigment. The only features of interest in the region $2000-4000 \mathrm{~cm}^{-1}$ are the peaks at $3030 \mathrm{~cm}^{-1}, 2922 \mathrm{~cm}^{-1}$ and $2850 \mathrm{~cm}^{-1}$ (Fig. SI2), which appear only for D-GC and E-GC, clearly ascribable to $\mathrm{C}-\mathrm{H}$ stretching in aliphatic and aromatic compounds, which result from the presence of the vehicle. However, the $\mathrm{C}-\mathrm{H}$ stretching in aromatic rings may also derive from an incomplete halogenation of
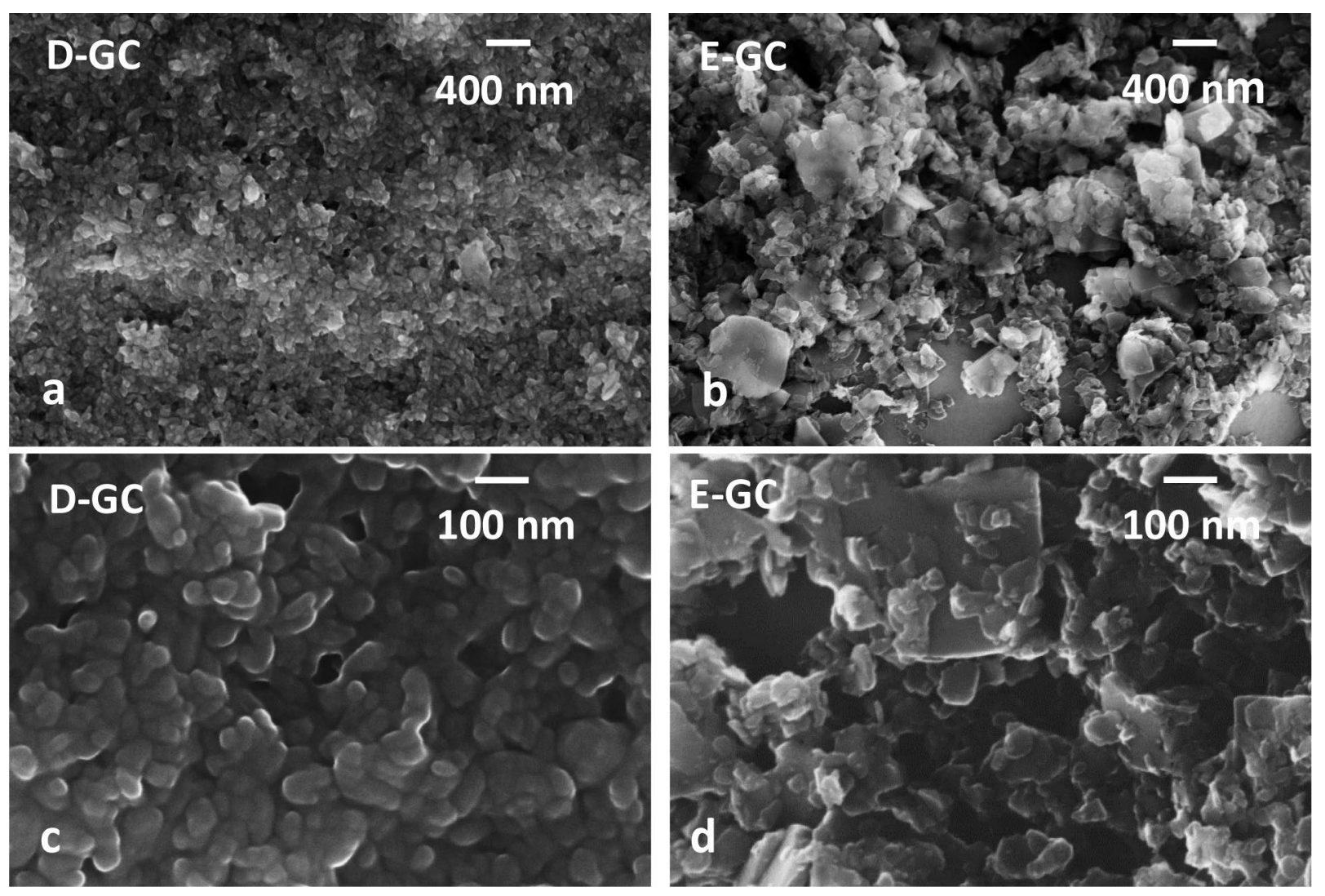

Fig. 2 SEM images of D-GC (a and $\mathbf{c})$ and E-GC (b and $\mathbf{d})$ at different magnifications 
the phthalocyanine, in the synthesis process of the pigments (Herbst and Hunger 2004).

\section{UV-Vis spectra}

UV-Vis spectra of D-GC, E-GC, PG36, and PG7 were taken in the range $300 \mathrm{~nm}$ to $800 \mathrm{~nm}$, in DMSO, which is a better dispersing agent (Fig. 1b), than ethanol, water and THF (Bauer et al. 2019) and ensures better-resolved spectra (peaks position and intensity are solvent-dependent). The UV-Vis spectrum of PG36 is distinguishable from the PG7 one, for the redshift of both Soret and Q band, due to the substitution of chlorine with bromine. Furthermore, the intensity ratio between the peaks in the $320 \mathrm{~nm}$ and $370 \mathrm{~nm}$ regions of PG7 is reverted as compared to PG36, and a shoulder at $640 \mathrm{~nm}$ is more pronounced. D-GC and E-GC display spectra similar to PG7, both for peaks positions and intensity.

\section{EDX analysis}

The EDX analysis was carried out on D-GC, E-CG and on the pigments of reference PG36 and PG7. The spectra are reported in the Supplementary Information, Fig. SI3. The PG7 spectrum is compatible with a chlorinated copper phthalocyanine. Two deviations from the theoretical composition, i.e. the excessive amount of carbon and the presence of oxygen, can be related to the toting of additives, to the way the sample is prepared, i.e. depositing from a suspension in ethanol, and to the contribution of the sample holder to the oxygen signal. In the PG36 spectrum the presence of the bromine is quite evident also due to the high crosssection. However, the $\mathrm{Br}: \mathrm{Cl}$ ratio is $3.5: 1$, i.e. much different than the nominal $\mathrm{Br}: \mathrm{Cl}=3: 5$, as in a hexabromodecachloro phthalocyanine. No bromine is evidenced in D-GC, or E-GC spectra, hence providing one more indication that PG7 is the pigment used in the ink formulation. Traces of $\mathrm{Al}$ in $\mathrm{D}-\mathrm{GC}$ can be ascribed to a dispersant agent (Bauer et al. 2019). The Si peak in two of the spectra is due to the silicon sample holder, not completely covered with the inks or pigments.
Occasional traces of fluorine can also be ascribed to the sample holder. The atomic percentages are reported in Table 1, normalized for the $\mathrm{Si}$ (or $\mathrm{Si}+\mathrm{F}$ ) signal, where necessary.

\section{SEM}

SEM images of the inks are reported in Fig. 2a-d. D-GC displays an extended sheath, with blunt grains inside of both elongated and roundish shapes. The aggregates of rod-like shape have the longest dimension ranging from $15 \mathrm{~nm}$ to $85 \mathrm{~nm}$; the roundish ones have diameters between $15 \mathrm{~nm}$ to $30 \mathrm{~nm}$ (Fig. 2a, c). Commercial PG7 was reported (Bucella et al. 2018) and presents mostly roundish aggregates with an average diameter of $70 \mathrm{~nm}$ (Fig. 2 of Bucella et al. 2018). On the other hand, the binding of substituents in meso positions of metal-phthalocyanines favors a rod-like aggregation (Wang et al. 2014). The sheath extends without disruption over the whole size of Fig. 2 a, i.e. $5 \times 5 \mu \mathrm{m}$ (and beyond in lower magnification non-shown images), and is damaged by interaction with the electron beam of the microscope, though operated at low power. This is shown in Fig. SI4 of the Supplementary Information, where the damaging appears as darkening upon swiping of an area, visible after subsequent imaging of a larger area at lower magnification. Upon treatment with sulfuric acid and re-precipitation, the sheath around the pigment is partially removed with consequent disruption of the extended, regular embedding structure (Fig. 2b, d). More important, large platelets appear, up to $0.5 \mu \mathrm{m} \times 0.5 \mu \mathrm{m}$ size, and, in general, lamellar structures are observed. The typical rod-like and roundish aggregates do not emerge.

\section{Ink after laser treatments}

Once established the pigment content of the ink, we preceded with the laser treatments of $\mathrm{D}-\mathrm{GC} / \mathrm{H}_{2} \mathrm{O}, \mathrm{E}-\mathrm{GC} / \mathrm{H}_{2} \mathrm{O}$, D-GC/P2OL, and E-GC/P2OL. We analyzed the residuals in the dispersion with several techniques to have an insight into both the composition and the morphology changes.
Table 1 EDX elemental analysis of PG7, PG36, D-GC and E-GC

\begin{tabular}{lcccc}
\hline Element & PG7 atomic $\%$ & PG36 atomic $\%$ & D-GC atomic $\%$ & E-GC atomic \% \\
\hline $\mathrm{C}$ & 63.0 & 84.3 & 69.5 & 61.2 \\
$\mathrm{~N}$ & 9.3 & 2.5 & 6.1 & 11.2 \\
$\mathrm{O}$ & 6.8 & 7.7 & 8.2 & 6.6 \\
$\mathrm{Br}$ & & 4.8 & & 19.6 \\
$\mathrm{Cl}$ & 19.8 & 1.4 & 15.2 & 1.3 \\
$\mathrm{Cu}$ & 1.1 & 0.3 & 0.8 & \\
$\mathrm{Al}$ & & & 0.2 & \\
\hline
\end{tabular}

The atomic $\% \mathrm{~s}$ are normalized for the contribution of the sample holder, i.e. the atomic \% of $\mathrm{Si}$ or $\mathrm{Si}+\mathrm{F}$ (PG36) 


\section{Gas chromatography/mass spectrometer}

The GC/mass spectra were taken every 10 min laser irradiation for all four dispersions. The peaks intensity of the chromatograms after $10 \mathrm{~min}$ and $20 \mathrm{~min}$ is marginal, therefore the analysis was carried out from 30 min irradiation onward. A careful analysis of the spectra revealed the presence of the same types of fragmentation compounds at an increasing extent as a function of the irradiation time. Therefore, we report the analysis of the $120 \mathrm{~min}$ irradiation spectra, only. The GC/mass spectra of D-GC/ $\mathrm{H}_{2} \mathrm{O}, \mathrm{E}-\mathrm{GC} / \mathrm{H}_{2} \mathrm{O}$, D-GC/P2OL, and E-GC/P2OL, after 120 min irradiation, along with a sketch of the corresponding identified fragment compounds are reported in Fig. 3. The eluted compounds were identified either through the NIST database or literature references (LaBrosse and Anderegg 1984; Giumanini et al. 1989) by pinpointing the mass fragmentation pattern with confidence $>95 \%$. The list of fragmentation products of the four samples upon $120 \mathrm{~min}$ irradiation is reported in Table 2, along with the retention time, the main mass losses corresponding to each compound, hazard class and category code. Most of the chlorinated compounds typical of the phthalocyanine fragmentation are eluted after $23 \mathrm{~min}$ retention time with differences among the four samples. The laser treatment of D-GC/ $\mathrm{H}_{2} \mathrm{O}$ and $\mathrm{E}-\mathrm{GC} / \mathrm{H}_{2} \mathrm{O}$ mostly produces isomers of tetrachloro-benzodinitrile. In addition, 1,3,5,7-tetrachloro naphthalene is generated from the treatment of $\mathrm{E}-\mathrm{GC} / \mathrm{H}_{2} \mathrm{O}$, whereas chlorobenzene is produced in $\mathrm{D}-\mathrm{GC} / \mathrm{H}_{2} \mathrm{O}$. The fragmentation pattern changes significantly in propan-2-ol. In D-GC/P2OL also tetrachloro benzene is produced, along with pentachloro benzene, 1,3,7-trichloro naphthalene, pentachloro benzonitrile, and diethyl phthalate, which are not present in the water dispersion counterpart. Overall, this scenario points at a more complex envelop of compounds due to fragmentation and rearrangement of the chlorinated indole units of the phthalocyanines. The fragmentation of E-GC/P2OL upon laser irradiation produces fewer fragment compounds as compared to D-GC/P2OL, i.e. tetrachlorobenzonitrile, pentachlorobenzonitrile, and diethyl phthalate.

The difference of produced compounds indicates a cooperative effect of the vehicle to the fragmentation upon laser irradiation, which is altered when the ink is partially stripped of the vehicle layer and the pigment is aggregated. There are two additional fragments, the 1,2,3,5-tetrachloro4-ethoxybenzene, and 2,3,5,6-tetrachloro-1-phenol which cannot be directly ascribed to the chlorinated phthalocyanine fragmentation and can possibly have two origins. They are either the outcome of an interaction with the solvent during the irradiation, or the residual of an additive. Two more considerations are in order at retention times below $5 \mathrm{~min}$. The 2,2'-(ethylidenebis(oxy)) bis-propane and 2,2'-(methylenebis(oxy)) bis-propane are generated in propan-2-ol which can be easily related to the irradiation of the solvent. Upon irradiation of the inks in a water solvent, hexene and heptene derivatives are eluted, non-compatible with the fragmentation pattern of chlorinated phthalocyanines. According to the label on the bottle and the SDS, the ink contains propan-2-ol and benzisothiazolinone alongside with witch hazel (or Hamamelis Virginiana extract CAS\# 68916). Hexene and derivatives are not compatible with the fragmentation upon irradiation of benzisothiazolinone (Varga et al. 2020) or propan-2-ol (Steinbach and Schmidt 1975), but not much can be asserted on witch hazel-derived additives, which are reported to contain a huge number of constituents (Safety Assessment 2017), none of them observed in this work and deemed harmless (Safety Assessment 2002). Other ways to introduce hexane derivatives in the ink are through the addition of antifriction agents in the pigment milling or through the pigment finishing procedure. It has been proposed that phthalocyanine laser treatments are thermic processes and, as such, produce the same fragment compounds as pyrolysis (Schreiver et al. 2015). Later on it was suggested that the main masses of the fragmentation compounds in ink treatments can be used for pigment identification, including PG7 among the detectable ones (Schreiver et al. 2016).

This kind of approach might have some limitations, because the types of compounds produced upon irradiation can be affected by the dispersing agent, in the first instance, and also by the vehicle or its residuals. To this purpose, we compared the products of fragmentation in this paper with the compounds produced upon the pyrolysis of PG7 at $800{ }^{\circ} \mathrm{C}$ (Germinario et al. 2015) and found some nonnegligible differences. In particular, the pyrolysis produces benzonitrile and derivatives, trichloro benzene, hexachlorobenzene, and diethyl phthalate, along with lower masses molecules such as benzene and tetrachloroethene we did not find in any of our treated samples. Other compounds such as tetrachlorobenzene and as tetrachlorobenzonitrile coincide in PG7 pyrolysis and laser-treated GC ink. The proposed identification of PG7 through the main fragments (identified through a single $\mathrm{m} / \mathrm{z}$ value per compound, Schreiver et al. 2016) foresees the singling out of 8 compounds listed in Table 3. We found only the two ones marked with a star in our treated inks. The absence of hydrogen cyanide and cyanogen chloride may be related to the lack of capturing gaseous fragments in our case. But, in general, relying on shortlisted fragments leaves room for incorrect identification of the pigment.

Safety issues of the fragments come on top of assignment issues, since the fragments generated upon laser treatments are toxic to various extent. The toxicological evaluation was made according to the Classification Labelling and Packaging (CLP) regulation (Classification, labelling and packaging regulation (CLP) at ECHA) issued by the REACH-ECHA 

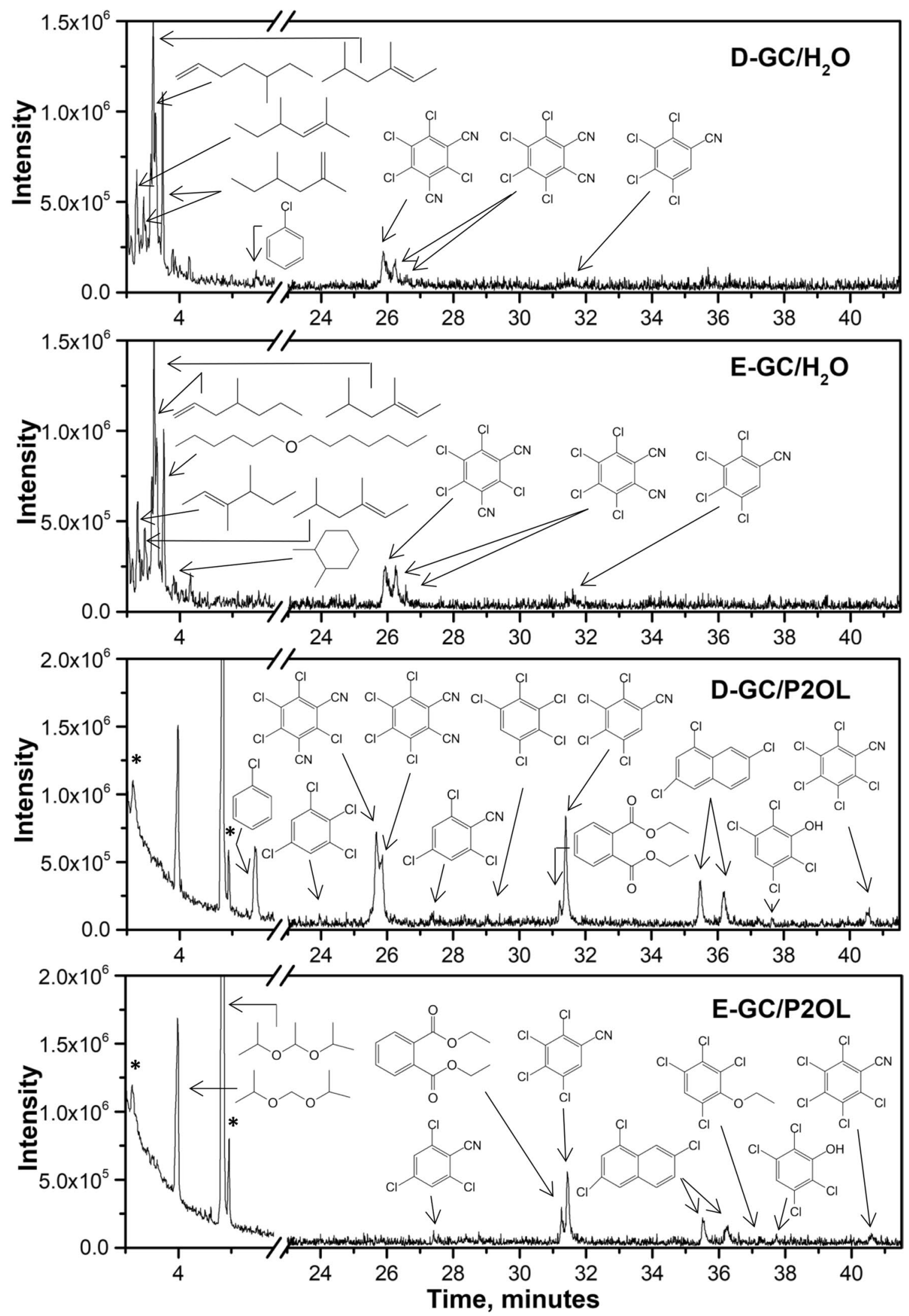
4Fig. $3 \mathrm{GC} / \mathrm{mass}$ spectra taken after $120 \mathrm{~min}$ irradiation of a D-GC/ $\mathrm{H}_{2} \mathrm{O}$, b E-GC/ $\mathrm{H}_{2} \mathrm{O}$, c D-GC/P2OL and d E-GC/P2OL. The sketch of the identified compounds is included in the corresponding panel. The * symbols indicate solvent-related peaks. The molecules corresponding to peaks observed at $3.97 \mathrm{~min}$ and $4.92 \mathrm{~min}$ of D-GC/P2OL and E-GC/P2OL are reported in the bottom panel only, for crowding reasons

and aligned with the Globally Harmonized System (GHS). The hazard code of each fragment is reported in the most right column of Table 2 and consists of a letter (typically $\mathrm{H}$ ) and a three digits number, which expresses the type of risk. The code is followed by a category, ranging from 1 to 4 indicating the level of danger: the lower the number, the higher the danger. Whether not available by the ECHA database, the hazard statements were taken from the CHEM SPACE associated database (CHEM SPACE). The exact correspondence between hazard code and associated risks is reported in Table SI2 of the Supplementary Information. The chlorinated compounds and the diethyl phthalate, directly deriving from the pigment fragmentation, display at least one of these three hazards codes, H312, H315 and H317, related to skin harm, irritation or allergy, respectively. Other hazards such as eye damage and irritation (H318, H319) may become relevant depending on the location of the tattoo. All chlorinated compounds but 1,2,3,5-tetrachloro benzene are classified as harmful if inhaled (H332). Diethyl phthalate and 2,4,5,6-tetrachloro-1,3-benzodinitrile also carry the codes H331 and $\mathrm{H} 330$, toxic and fatal if inhaled, respectively. If these fragments are produced under the skin, the effective harm, then, depends on the translocation from the skin to the blood and lymphatic vessels. 2,4,5,6-tetrachloro-1,3-benzodinitrile is also suspected carcinogenic (H351). As for the hexane derivatives, the available hazard codes mainly indicate flammability besides causing skin irritation or drowsiness or dizziness.

\section{UV-Vis spectra}

UV-Visible spectra were recorded on the solutions after laser treatments. In Fig. 4a-d the spectra after 60 min irradiation are reported, in comparison with the corresponding non-treated samples (some of the intensities at $120 \mathrm{~min}$ irradiation are too low to display). As far as the samples in water are concerned, the features before and after irradiation can be largely described as an overall decrease of intensity. The copper phthalocyanine (CuPc) UV-Vis spectral intensity is related to the aggregation state. It increases whether the $\mathrm{CuPc}$ dispersion forms aggregates of a size which can remain as a suspension in the solvent (Wang et al. 2010; Kihara et al. 2019). In case the CuPc is fragmented and/or forms aggregate too large to remain in suspension, the intensity decreases. The samples irradiated in propan2-ol, not only display a marked reduction of the ink-related intensity, but a new feature is also present, peaked at $708 \mathrm{~nm}$, which is not typical of the ink, nor of any of the fragments detected by GC-mass spectrometry. This newly emerged feature can be ascribed to $\mathrm{Cu}$ octachlorophthalocyanate (Barret et al. 1939), a compound that has been reported as "inactive" by EPA (TSCA Inventory 2020) and is under registration by the REACH-ECHA since 2009 (ECHA substance Infocard). It cannot be ascertained, at this stage, whether this is a product of a laser-induced de-halogenation of the PG7, or if it is a by-product already present in the ink and emerged by removal of the PG7 features. The C-H stretching in the infrared spectra does suggest the incompletely halogenated phthalocyanine is already there. Either way, this feature emerges better upon ink treatment in propan-2-ol.

\section{SEMs: fragmentation vs. aggregation}

Along with GC/mass and UV-Vis spectrometroscopies, the irradiated samples were analyzed by SEM, to appraise the average size of the solid residuals and their morphology. At the end of the process several types of fragments and aggregates can be observed along with different damages of the sheath originally around the phthalocyanine grains. SEM images of D-GC/ $\mathrm{H}_{2} \mathrm{O}, \mathrm{E}-\mathrm{GC} / \mathrm{H}_{2} \mathrm{O}, \mathrm{D}-\mathrm{GC} / \mathrm{P} 2 \mathrm{OL}$ and E-GC/ P2OL, upon 120 min irradiation are reported in Fig. 5a-1. The overall set of morphology-related phenomena is summarized as follows:

- Downsizing;

- Change of texture of the sheath, or residual sheath around the phthalocyanines;

- Aggregations in "blocks";

- Aggregation in compact structures;

- Aggregation in layered structures;

- Aggregation in radially distributed fiber structures;

- Aggregation in flower-like structures.

The first three effects are common to all the samples, whereas the other ones are more peculiar of single types of samples. More in detail, in all treated samples we clearly found nanoparticles with size in the $20-30 \mathrm{~nm}$ range, but the presence of even smaller nanoparticles in the order of 2-3 nm could be evidenced by contrast enhancement of selected areas of high magnification SEM images. This feature is highlighted in Fig. 5a for the sample D-GC/ $\mathrm{H}_{2} \mathrm{O}$. Other features common to all the samples are the aggregations in blocks, i.e. large agglomerates in the micrometer range as shown in Fig. $5 b$ for the sample D-GC/ $\mathrm{H}_{2} \mathrm{O}$ and the changes of the texture of the overall solid residual. The textures upon laser treatments may be characterized by a prevalent merging and flattening of the structures as in Fig. 5c D- $\mathrm{GC} / \mathrm{H}_{2} \mathrm{O}$. A characteristic feature of the $\mathrm{E}-\mathrm{GC} / \mathrm{H}_{2} \mathrm{O}$ sample is the additional population of agglomerates in the $350 \pm 100 \mathrm{~nm}$ range (Fig. 5d) while the $\mathrm{D}-\mathrm{GC} / \mathrm{H}_{2} \mathrm{O}$ sample 
Table 2 Fragment compounds produced upon laser treatment, along with the retention times, the main mass losses and the corresponding hazard codes and categories

\begin{tabular}{|c|c|c|c|c|c|c|}
\hline Compound & $\begin{array}{l}\mathrm{D}-\mathrm{GC} / \mathrm{H}_{2} \mathrm{O} \\
\mathrm{RT}(\min )\end{array}$ & $\begin{array}{l}\text { E-GC/ } \mathrm{H}_{2} \mathrm{O} \\
\mathrm{RT}(\min )\end{array}$ & $\begin{array}{l}\text { D-GC/ } \\
\text { P2OL RT } \\
(\min )\end{array}$ & $\begin{array}{l}\text { E-GC/ } \\
\text { P2OL RT } \\
(\min )\end{array}$ & Main $m / z$ & $\begin{array}{l}\text { Hazard class and category } \\
\text { code }\end{array}$ \\
\hline 3,4-Dimethyl-2-hexene & l & 3.20 & l & I & $112,97,83,69,55,27$ & NF \\
\hline 2,4-Dimethyl-2-hexene & 3.20 & / & l & l & $\begin{array}{l}112,97,83,69,55,43,41 \\
29,27\end{array}$ & $\begin{array}{l}\text { H225 Flam. Liq. Cat. } 2 \\
\text { H304 Asp. Tox. Cat. } 1\end{array}$ \\
\hline 2,4-Dimethyl-1-hexene & $\begin{array}{l}3.33 \\
3.68\end{array}$ & l & l & l & $\begin{array}{l}112,83,70,69,57,56,55 \\
\quad 41,29,27\end{array}$ & $\begin{array}{l}\text { H225 Flam. Liq. Cat. } 2 \\
\text { H304 Asp. Tox. Cat. } 1\end{array}$ \\
\hline 5-Methyl-1-heptene & 3.46 & / & l & l & $\begin{array}{c}112,83,71,70,69,57,55 \\
43,42,41,29,27\end{array}$ & $\mathrm{NF}$ \\
\hline 4-Methyl-1-heptene & l & 3.47 & l & / & $71,70,55,43,39,29,27$ & NF \\
\hline 3,5-Dimethyl-2-hexene & 3.50 & 3.52 & I & l & $112,97,83,70,69,55,27$ & NF \\
\hline Heptil hexyl ether & l & 3.70 & l & / & $85,70,57,43,29$ & NF \\
\hline 1,2-Dimethyl-cyclohexane & l & 3.89 & l & l & $112,97,70,69,56,55,27$ & $\begin{array}{l}\text { H225 Flam. Liq. Cat. } 2 \\
\text { H304 Asp. Tox. Cat. } 1 \\
\text { H315 Skin Irr. Cat. } 2 \\
\text { H336 STOT SE Cat. } 3\end{array}$ \\
\hline $\begin{array}{l}2,2^{\prime} \text {-(Methylenebis(oxy)) bis- } \\
\text { propane }\end{array}$ & / & / & 3.97 & 3.99 & $\begin{array}{l}131,117,89,87,73,59,51 \\
45,43,41,39,27,15\end{array}$ & $\begin{array}{l}\text { H225 Flam. Liq. Cat. } 2 \\
\text { H315 Skin Irr. Cat. } 2 \\
\text { H319 Eye Irr. Cat. } 2 \\
\text { H335 STOT SE Cat. } 3\end{array}$ \\
\hline $\begin{array}{l}2,2^{\prime} \text {-(Ethylidenebis(oxy)) bis- } \\
\text { propane }\end{array}$ & l & l & 4.82 & 4.84 & $\begin{array}{l}131,89,87,69,61,59,58 \\
45,43,41,27\end{array}$ & $\mathrm{NF}$ \\
\hline Chloro benzene & 5.44 & / & 5.43 & / & $114,112,77,51,50,38$ & $\begin{array}{l}\text { H226 Flam. Liq. Cat. } 3 \\
\text { H315 Skin Irr. Cat. } 2 \\
\text { H332 Acute Tox. Cat. } 4\end{array}$ \\
\hline 1,2,3,5-Tetrachloro benzene & & & 23.95 & & $\begin{array}{l}220,218,216,214,181,108 \\
\quad 74,73\end{array}$ & H302 Acute Tox. Cat. 4 \\
\hline $\begin{array}{l}\text { 3,4,5,6-Tetrachloro-1,2-ben- } \\
\text { zonitrile }\end{array}$ & $\begin{array}{l}25.88 \\
26.25\end{array}$ & $\begin{array}{l}25.90 \\
26.24 \\
26.59\end{array}$ & $\begin{array}{l}25.68 \\
25.89\end{array}$ & l & $\begin{array}{c}270,268,266,264,233,231 \\
229,196,194,168,159 \\
133,124,118,109,98\end{array}$ & $\begin{array}{l}\text { H312 Acute Tox. Cat. } 4 \\
\text { H315 Skin Irr. Cat. } 2 \\
\text { H319 Eye Irr. Cat. } 2 \\
\text { H332 Acute Tox. Cat } 4\end{array}$ \\
\hline $\begin{array}{l}\text { 2,4,5,6-Tetrachloro-1,3-ben- } \\
\text { zonitrile }\end{array}$ & $\begin{array}{l}25.88 \\
26.25\end{array}$ & 26.24 & $\begin{array}{l}25.68 \\
25.89\end{array}$ & l & $\begin{array}{c}270,268,266,264,233,231 \\
229,196,194,168,159 \\
133,124,118,109,98\end{array}$ & $\begin{array}{l}\text { H317 Skin Sens. Cat. } 1 \\
\text { H318 Eye Dam. Cat. } 1 \\
\text { H330 Acute Tox. Cat. } 2 \\
\text { H335 STOT SE Cat. } 3 \\
\text { H351 Carc. Cat. } 2\end{array}$ \\
\hline 2,4,6-Trichloro-1-benzonitrile & l & / & 27.34 & 27.41 & $\begin{array}{l}209,207,205,170,134,109 \\
\quad 50,37\end{array}$ & $\begin{array}{l}\text { H302 Acute Tox./ } \\
\text { H312 Acute Tox./ } \\
\text { H315 Skin Irr. Cat. } 2 \\
\text { H319 Eye Irr. Cat. } 2 \\
\text { H332 Acute Tox./ } \\
\text { H335 STOT SE Cat. } 3\end{array}$ \\
\hline Pentachloro benzene & l & l & 29.05 & l & $254,252,250,248$ & $\begin{array}{l}\text { H228 Flam. Sol. Cat. } 1 \\
\text { H302 Acute Tox. Cat. } 4\end{array}$ \\
\hline Diethyl phthalate & l & l & 31.22 & 31.26 & $\begin{array}{l}222,177,176,150,149,121 \\
\quad 105,104,76,65,50\end{array}$ & $\begin{array}{l}\text { H315 Skin Irr. Cat. } 2 \\
\text { H319 Eye Irr. Cat. } 2 \\
\text { H331 Acute Tox. Cat. } 3 \\
\text { H373 STOT RE } 2 \text { Cat. } 2\end{array}$ \\
\hline $\begin{array}{l}\text { 2,3,4,5-Tetrachloro benzoni- } \\
\text { trile* }\end{array}$ & 31.62 & 31.62 & 31.40 & 31.44 & $245,243,241,239$ & $\begin{array}{l}\text { H302 Acute Tox. Cat. } 4 \\
\text { H312 Acute Tox. Cat. } 4 \\
\text { H315 Skin Irr. Cat. } 2 \\
\text { H319 Eye Irr. Cat. } 2 \\
\text { H332 Acute Tox.Cat. } 4 \\
\text { H335 STOT SE Cat. } 3\end{array}$ \\
\hline
\end{tabular}


Table 2 (continued)

\begin{tabular}{|c|c|c|c|c|c|c|}
\hline Compound & $\begin{array}{l}\mathrm{D}-\mathrm{GC} / \mathrm{H}_{2} \mathrm{O} \\
\mathrm{RT}(\min )\end{array}$ & $\begin{array}{l}\mathrm{E}-\mathrm{GC} / \mathrm{H}_{2} \mathrm{O} \\
\mathrm{RT}(\min )\end{array}$ & $\begin{array}{l}\text { D-GC/ } \\
\text { P2OL RT } \\
\text { (min) }\end{array}$ & $\begin{array}{l}\text { E-GC/ } \\
\text { P2OL RT } \\
(\min )\end{array}$ & Main $m / z$ & $\begin{array}{l}\text { Hazard class and category } \\
\text { code }\end{array}$ \\
\hline 1,3,7-Trichloro naphthalene & I & / & 35.46 & $\begin{array}{l}35.51 \\
36.19\end{array}$ & $234,232,230,197,195,160$ & $\begin{array}{l}\text { H302 Acute Tox. Cat. } 4 \\
\text { H312 Acute Tox. Cat. } 4 \\
\text { H315 Skin Irr. Cat. } 2 \\
\text { H319 Eye Irr. Cat. } 2 \\
\text { H332 Acute Tox. Cat. } 4 \\
\text { H335 STOT SE Cat. } 3\end{array}$ \\
\hline $\begin{array}{l}\text { 1,2,3,5-Tetrachloro-4-ethoxy } \\
\text { benzene }\end{array}$ & l & / & / & 37.64 & $260,236,234,232,230$ & NF \\
\hline 2,3,5,6-Tetrachloro-1-phenol & / & / & 37.73 & 37.73 & $236,234,232,230$ & $\begin{array}{l}\text { H301 Acute Tox. Cat. } 3 \\
\text { H315 Skin Irr. Cat. } 2 \\
\text { H318 Eye Dam. Cat. } 1 \\
\text { H335 STOT SE Cat. } 3\end{array}$ \\
\hline Pentachloro benzonitrile & l & / & 40.50 & 40.59 & $\begin{array}{l}279,277,275,273,242 \\
240,238,205,203,133 \\
118\end{array}$ & $\begin{array}{l}\text { H302 Acute Tox. Cat. } 4 \\
\text { H312 Acute Tox. Cat. } 4 \\
\text { H315 Skin Irr. Cat. } 2 \\
\text { H319 Eye Irr. Cat. } 2 \\
\text { H332 Acute Tox. Cat. } 4 \\
\text { H335 STOT SE Cat. } 3\end{array}$ \\
\hline
\end{tabular}

The identification was performed by inquiry of the NIST database

*This compound was identified through literature data (Giumanini et al. 1989; LaBrosse and Anderegg 1984)

also shows layered and compact structures (Fig. 5e-g). Compact structures are typically rectangular, in the order of the hundreds of nanometers, without evident inner features, as if the original sheathed grains or portions of them were tightly melted all together. Two types of layered structures were evidenced, the degrading ones where the layers stacked one on top of the other, mutually shifting in the plane perpendicular to the stacking directions (Fig. 5e), and the open ones where the layers are folded in random directions (Fig. 5f). The radial structures pertain to $\mathrm{E}-\mathrm{GC} / \mathrm{H}_{2} \mathrm{O}$ sample and it is formed of fibers radially arranged around a fulcrum (Fig. $5 \mathrm{~g}$ ). The aspect ratio of the generated fibers ranges

Table 3 Main pyrolysis compounds proposed for PG7 identification according to Schreiver et al. (2016)

\begin{tabular}{lc}
\hline Fragments & $\mathrm{m} / \mathrm{z}$ \\
\hline Hydrogen cyanide & 36 \\
Cyanogen chloride & 61 \\
Carbon tetrachloride & 152 \\
Tetrachloroethylene & 164 \\
Hexachlorobenzene & 282 \\
Pentachlorobenzonitrile* & 273 \\
3,4,5,6-Tetrachloro-1,2-benzonitrile* & 266 \\
4,5,6,7-Tetrachloroisoindoline & 257 \\
\hline
\end{tabular}

This table is reported from with modifications

The star* indicates the fragments in common with the present investigation between 10 and 40, with the smallest dimension of typically $1 \mu \mathrm{m}$. Fiber structures are also generated upon irradiation of D-GC/P2OL samples, though with a fiber arrangement in a flower-like over-structure, (Fig. 5h) sized in the micrometer range. Along with this, a peculiar texture is observed with more pronounced melting and hollow appearance (Fig. $5 \mathrm{j}$ ) with blocks islands in between (Fig. 5i). EDX analyses carried out of the various solid deposits revealed the presence of chlorine both in the solid residue and in the deformed sheathed structures, indicating the incorporation either of non-fragmented phthalocyanines or of chlorinated fragments or a mixture of both. Additional features of the D-GC/P2OL sample are coalescing blocks (Fig. 5k) and areas of pierced solvent with large pores (Fig. 51).

The processes taking place during the irradiation, leading to the morphology changes are likely related both to the temperature at the focusing spot and to the solvent. It must be added that the Brownian movement of the dispersion accelerates during the irradiation, with effective mixing within the volume of the dispersion and consequent temperature gradient. The downsizing is common to all inks/solvent combinations and it is likely to be an effective pathway in the tattoo removal process. The aggregation processes and sheath deformations are possibly the combined effects of heating and beam piercing, affecting pigment and vehicle (or vehicle residual for the extracted ink) simultaneously. CuPcs aggregation by physical vapor deposition is commonly used for the synthesis of air-stable n-type semiconductors. Nanorods formation has been 
reported to be induced by Nd:YAG laser treatment of copper hexadecafluoro phthalocyanine $\left(\mathrm{F}_{16} \mathrm{CuPc}\right)$ as a function of time and solvent (Kihara et al. 2019). In this case, the length and aspect ratio of the rods, was correlated to the solvent viscosity, i.e. the lower the viscosity, the longer the rods, (the faster they were formed). Temperature effects play a role in the production of ultralong CuPc fibers. Synthesis was carried out by differential heating under nitrogen in a tubular quartz chamber set at $480{ }^{\circ} \mathrm{C}, 440{ }^{\circ} \mathrm{C}$, and $180{ }^{\circ} \mathrm{C}$ in different zones each $30 \mathrm{~cm}$ long (Wang et al. 2010) and yielded fibers up to $1.4 \mathrm{~cm}$. Flower-like arrangements are also reported, but they are generated by electrospinning of hyperbranched iron phthalocyanines with the addition of polyarylene ether nitriles (Meng and Liu 2014). The major differences are the building blocks, which appear to be fibers in the present investigation, rather than the nano-petals as reported by Meng and Liu (2014).

In the present investigation, we find fiber structures in the micrometer range for the sample $\mathrm{E}-\mathrm{GC} / \mathrm{H}_{2} \mathrm{O}$, thus supporting the proposed mechanism that favors the formation of longer structures in lower viscosity solvents (water is less viscous than propan-2-ol). However, this kind of growth is only possible if the ink is partially stripped from the vehicle.
Fig. 5 SEM images of D-GC/ $\mathrm{H}_{2} \mathrm{O}, \mathrm{E}-\mathrm{GC} / \mathrm{H}_{2} \mathrm{O}, \mathrm{D}-\mathrm{GC} / \mathrm{P} 2 \mathrm{OL}, \mathrm{E}-\mathrm{GC} / \boldsymbol{}$ $\mathrm{P} 2 \mathrm{OL}$, after 120 min laser treatment. a-c Selected for the samples reported on the top left of each panel, but they represent morphologies common to all the treated samples. e-l Morphologies typical of the sample indicated on the top left of each panel

The D-GC/ $\mathrm{H}_{2} \mathrm{O}$ laser-treated sample presents a peculiar compact and layered structures that indicate a contribution of the vehicle in keeping the structure tight along the layer plane and across planes. In a higher viscous and less polar solvent, the aggregation is no longer of the rod type, but it occurs only in blocks with a reduced presence of the vehicle (E-GC/P2OL, common morphologies). If the vehicle is present, the laser treatment in propan-2-ol (D-GC/P2OL) leads to a mixed situation where small fibers in the low $\mu \mathrm{m}$ range are arranged in a flower-like shape and branching additives also play a role. All in all the generated morphologies are quite heterogeneous and some of them potentially harmful when in contact with the skin, or when ejected from the skin. In particular, small nanoparticles are candidates for toxic to carcinogenic reactions (Schröder et al. 2014), whereas large blocks are deemed to be less risky. The fibers might be dangerous due to their large aspect ratio. Asbestos
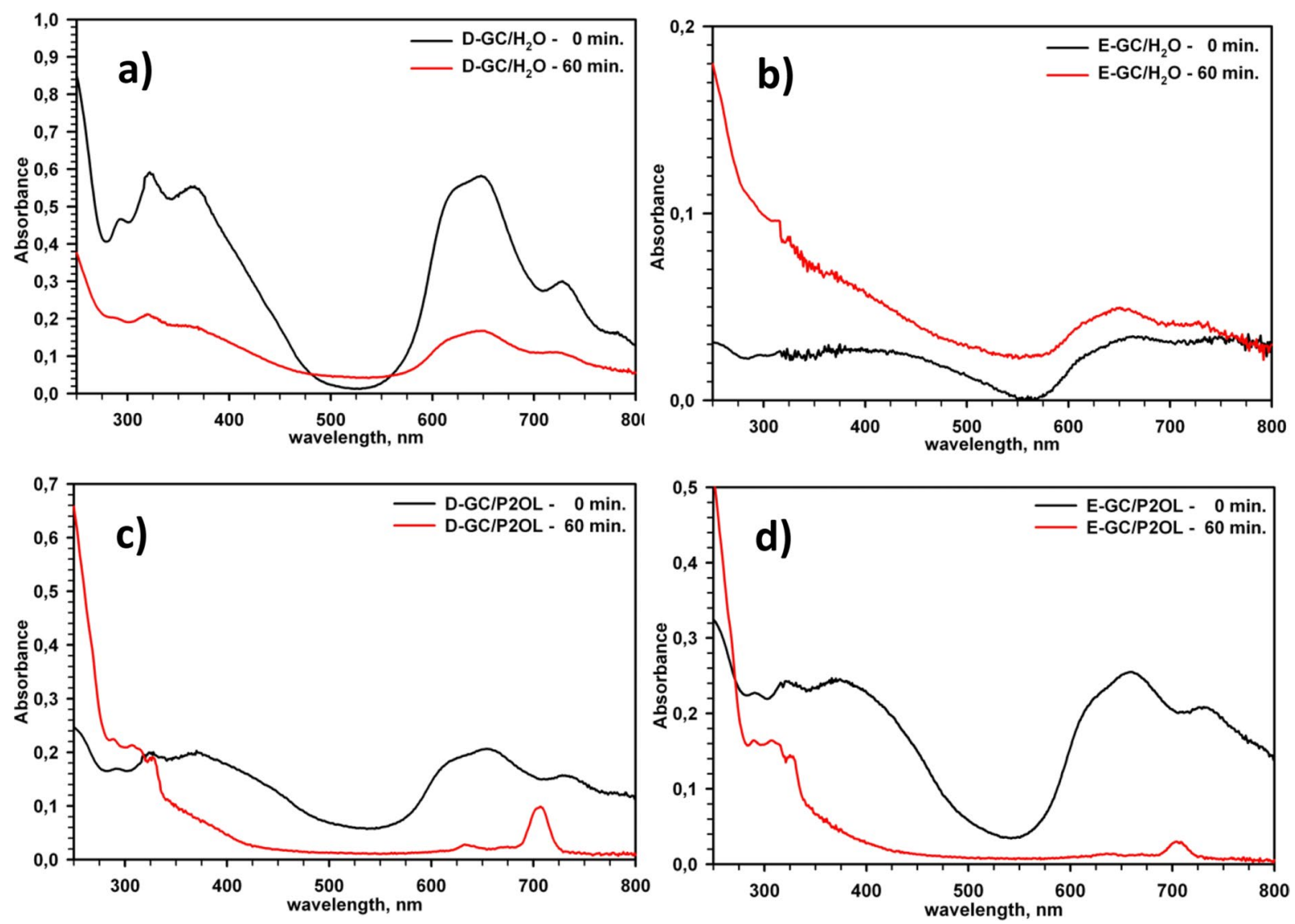

Fig. 4 UV-Vis spectra before and after 60 min laser irradiation: a D-GC/ $\mathrm{H}_{2} \mathrm{O}$, b E-GC/ $\mathrm{H}_{2} \mathrm{O}, \mathbf{c} \mathrm{D}-\mathrm{GC} / \mathrm{P} 2 \mathrm{OL}$ and d E-GC/P2OL 

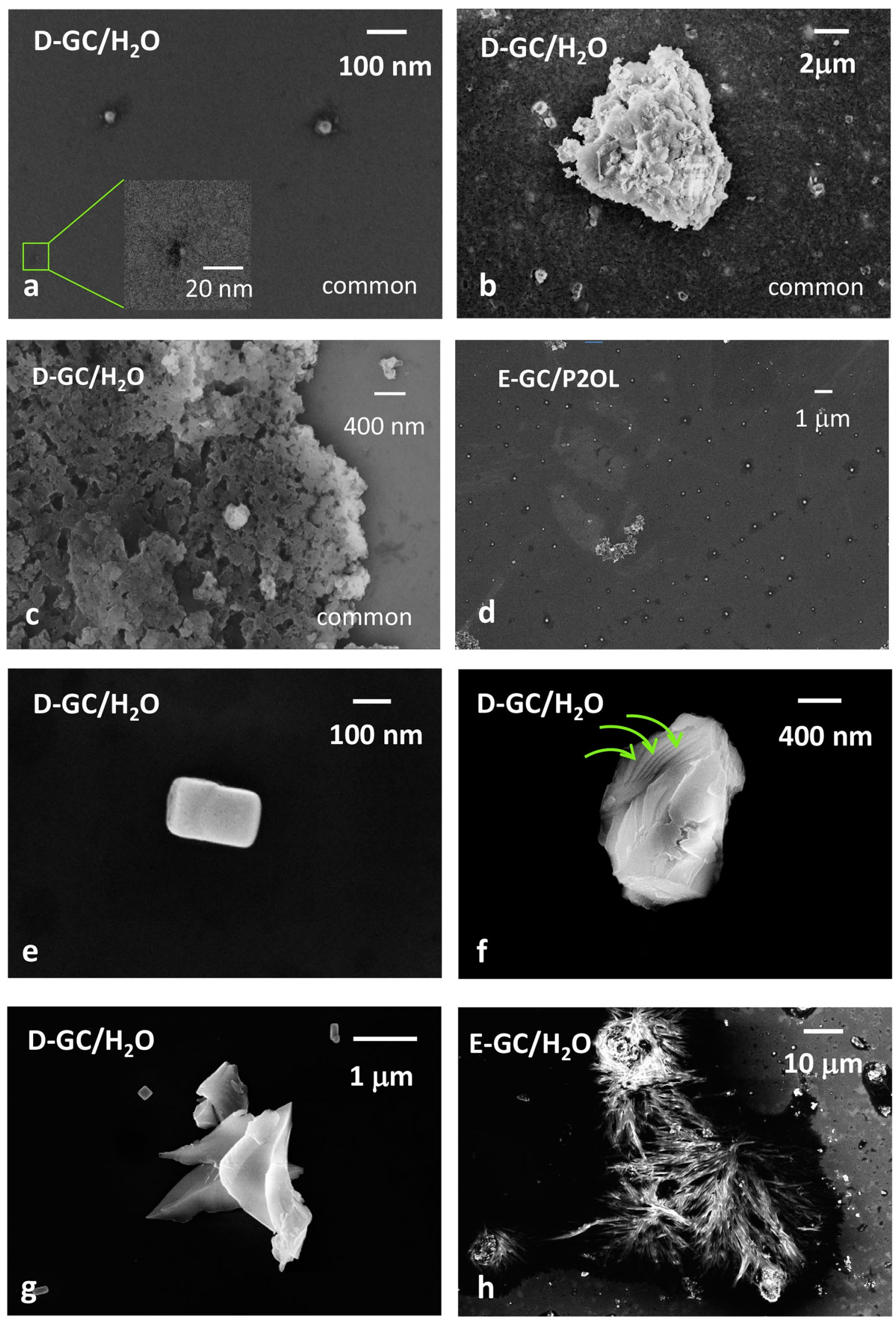

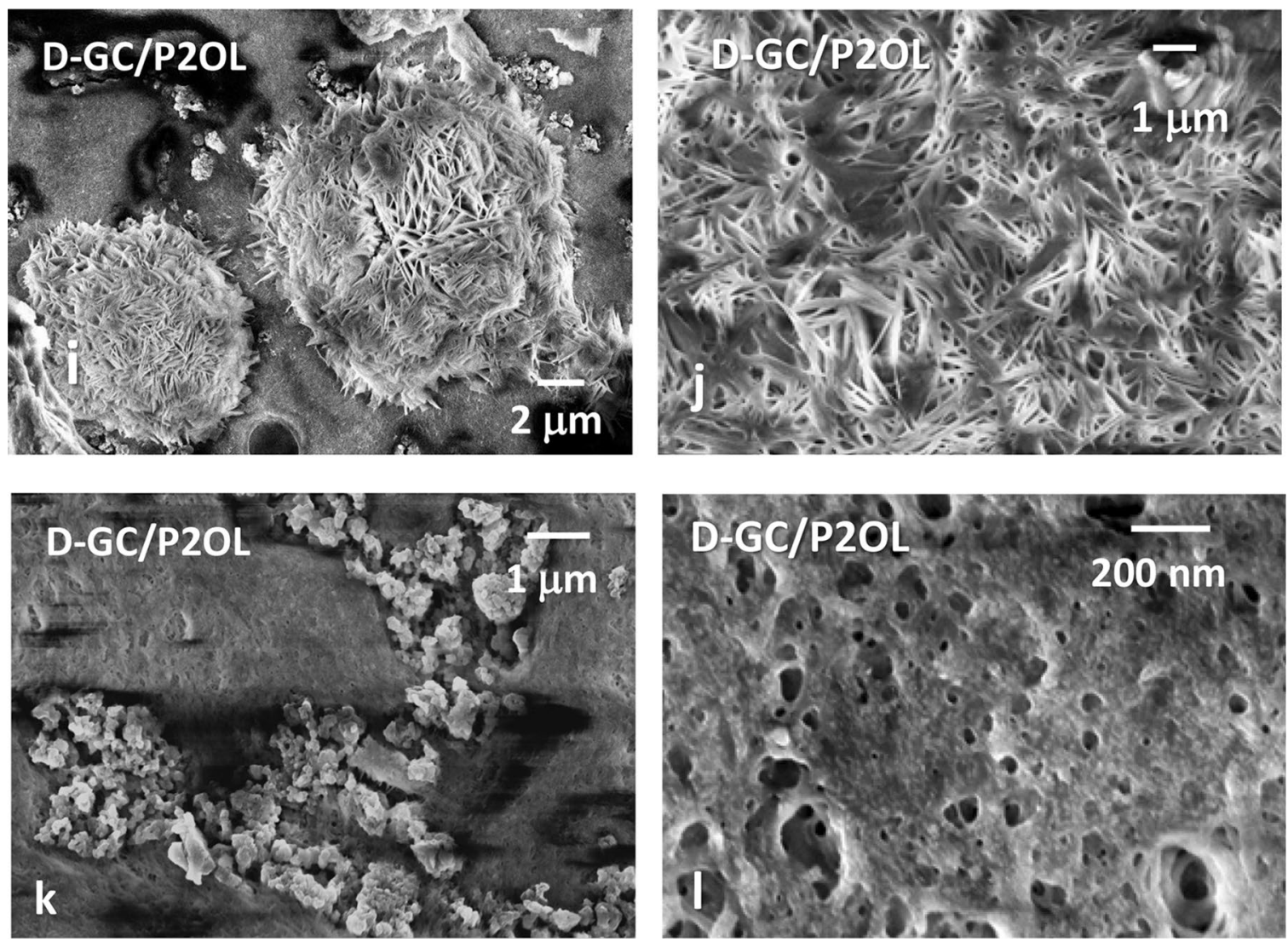

Fig. 5 (continued)

Table 4 Average hydrodynamic diameter $2 R_{\mathrm{H}}$ from DLS measurements on D-GC/ $\mathrm{H}_{2} \mathrm{O}$, E-GC/ $\mathrm{H}_{2} \mathrm{O}$, D-GC/P2OL, and E-GC/P2OL after 120 min laser treatment, determined by cumulant analysis and intensity-weighted size distribution by NNLS algorithm

\begin{tabular}{|c|c|c|c|c|}
\hline Sample & $2 R_{\mathrm{H}}(\mathrm{nm})$ (cumulant) & PDI (cumulant) & 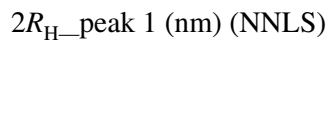 & $\begin{array}{l}2 R_{\mathrm{H} \_ \text {peak }} \\
2(\mathrm{~nm}) \\
(\mathrm{NNLS})\end{array}$ \\
\hline $\mathrm{D}-\mathrm{GC} / \mathrm{H}_{2} \mathrm{O}$ & $5100 \pm 680$ & $0.560 \pm 0.080$ & $1320 \pm 20$ & $8000 \pm 1000$ \\
\hline $\mathrm{E}-\mathrm{GC} / \mathrm{H}_{2} \mathrm{O}$ & $1330 \pm 16$ & $0.391 \pm 0.010$ & $1030 \pm 28$ & $7500 \pm 1000$ \\
\hline D-GC/P2OL & $2500 \pm 90$ & $0.250 \pm 0.015$ & $2700 \pm 50$ & - \\
\hline E-GC/P2OL & $5300 \pm 60$ & $0.814 \pm 0.026$ & $353.5 \pm 5.8$ & $8600 \pm 20$ \\
\hline
\end{tabular}

fibers are considered most toxic when their aspect ratio is $>5$ (Boulanger et al. 2014). Carbon nanotubes (CNTs) also have toxicity issues in the skin due to inflammatory reactions and even tissue disruption, though damages are reported also for organs and brain (Mohanta et al. 2019), the longer the nanotube, the more toxic. The aspect ratio of CNTs can be as high as 500, with the smallest dimension down to $10 \mathrm{~nm}$. The actual toxicity of the fibers is an association of composition and aspect ratio, and the generation of the fiber alone is not sufficient to determine the real harm. Part of the vehicle sheath may act as a protective coating against potential harm. On the other hand, the aggregates, including the fiber-shaped ones, do contain chlorinated compounds, possibly the toxic ones too. The fiber-shaped aggregates may act as needles able to inoculate the toxic fragments, thus operating as carriers of toxic compounds, even though they are not harmful themselves.

\section{DLS}

The average size and size distribution were evaluated by DLS for samples treated for $120 \mathrm{~min}$. The results of analysis of DLS measurements are reported in Table 4 , where $2 R_{\mathrm{H}}$ and PDI represent the mean value of hydrodynamic diameter and the polydispersity, respectively, obtained from cumulant analysis. $2 R_{\mathrm{H}}$-Peak 1 and $2 R_{\mathrm{H}}$-Peak 2 refer to the 
mean values of the two distributions obtained by intensityweighted NNLS analysis. It is immediately apparent that the DLS size of the ink dispersions are very heterogeneous, with a behavior depending both on sample and solvent. As a preliminary observation, it is important to note that D-GC/ P2OL sample has the lowest PDI, with respect to the other inks, thus indicating a comparatively higher homogeneity of this dispersion. The associated NNLS distribution analysis confirms the homogeneity of this sample by indicating the presence of a single population with an average size of $2700 \mathrm{~nm}$. This value is in agreement with values obtained by cumulant analysis, the slight difference being dependent on the used method. The micrometric objects revealed by DLS can be easily identified with the well-separated roundish fibrous aggregates (Fig. 5i) or aggregates formed by more compact blocks, coalescing due to dehydration and flattening (Fig. 5k). On the other hand, samples with PDI index larger than 0.3 are characterized by two distinct populations with very different size, as revealed by NNLS analysis. In all these samples, large aggregates with the size of several microns (Peak 2) coexist with smaller aggregates (Peak 1), with an evident difference between E-GC/P2OL and E-GC/ $\mathrm{H}_{2} \mathrm{O}$. Notably, in E-GC/P2OL the smaller objects show a hydrodynamic size well below that of the inks dispersed in water, thus confirming the effect of the viscosity of the solvent in the final size of the aggregates forming after laser treatment. SEM microscopy gives evidence of this important difference. Small objects with submicron size are observed for E-GC/P2OL (Fig. 5d) coexisting with larger aggregates. The micrometric aggregates found in $\mathrm{E}-\mathrm{GC} / \mathrm{H}_{2} \mathrm{O}$ are representative of the different micrometric agglomerates with layered or more compact structures found by SEM investigation (Fig. 5b, e-h).

In conclusion, it is important to note that in such heterogeneous samples, DLS is not able to reveal the presence of objects with a size smaller than $100 \mathrm{~nm}$, which are observed in all the samples, as common structures (Fig. 5a). In spite of their relatively large number, as visible in SEM image, since in the DLS technique the scattering intensity according to Mie theory has a power-law dependence on the radius, it is reasonable that the scattering contribution of the larger aggregates completely masks one of the smaller structures observed by SEM.

\section{Conclusions}

We have investigated the composition and Nd:YAG laser treatments of a phthalocyanine based green tattoo ink, the Green Concentrate from Eternal Ink Inc. The ink characterization points at the presence of pigment, the PG7, different from the PG36 reported on the bottle label and restricted in the countries where tattoo inks regulations are issued.
An extraction with sulfuric acid and re-precipitation with water has been carried out to remove, at least partially, the vehicle from the ink and to release the pigment, as it may be the case upon injection under the skin. The laser treatments were performed both on dried and on extracted ink dispersed either in water or in propan-2-ol, solvents of different polarities and viscosities. The laser irradiation causes fragmentations of the green pigment and variations of the morphology of the ink aggregates, in terms of both size reduction and re-aggregations. Both processes are solvent dependent and differences can be reconducted to the initial sample, whether it is dried or extracted ink. The fragment compounds generated upon laser irradiation are toxic according to the Classification Labelling and Packaging regulations issued by the REACH-ECHA. The hazard statements include skin harm, irritation or allergy, which may be toxic or fatal if inhaled, cause eye damage, and irritation. One of the fragments, the 2,4,5,6-tetrachloro-1,3-benzonitrile, is suspected carcinogenic. Additional hexene derivatives fragments can be related to ink additives and carry lower risks. The morphology of the laser-treated samples is very heterogeneous, and includes nanoparticles in the $20-30 \mathrm{~nm}$ range and lower, hence potentially harmful when produced under the skin. The re-aggregation in blocks is common to all samples, whereas layered compounds, fibers, and flower-like arranged microfibers are typical of the ink-solvent specific combinations. Fibers, in particular, are exclusively found for the extracted ink sample dispersed in water (low viscosity, high polarity solvent).

\section{Compliance with ethical standards}

Conflict of interest The authors declare that they have no conflict of interest.

\section{References}

Achar BN, Mohan Kumar TM, Lokesh KS (2007) Synthesis, characterization, pyrolysis kinetics and conductivity studies of chloro substituted cobalt phthalocyanines. J Coord Chem 60:1833-1846

Anderson R, Parrish J (1983) Selective photothermolysis: precise microsurgery by selective absorption of pulsed radiation. Science 220:524-527

Ara G, Anderson R, Mandel K, Ottesen M, Oseroff AR (1990) Irradiation of pigmented melanoma cells with high intensity pulsed radiation generates acoustic waves and kills cells. Lasers Surg Med 10:52-59

Barret PA, Bradrook EF, Dent CE, Linstead RP (1939) Phthalocyanines and related compounds. Part XVI. The halogenation of phthalocyanines. J Chem Soc 1820-1828

Barszcz B, Bogucki A, Biadasz A, Bursa B, Wróbel D, Graja A (2011) Molecular orientation and spectral investigations of 
Langmuir-Blodgett films of selected copper phthalocyanines. J Photochem Photobiol A 218:48-57

Bauer EM, De Caro T, Tagliatesta P, Carbone M, (2019) Unraveling the real pigment composition of tattoo inks: the case of bi-components phthalocyanine based greens. Dyes Pigm 167:225-235

Berne BJ, Pecora R (2000) Dynamic light scattering: with applications to chemistry, biology, and physics. Courier Corporation, North Chelmsford

Bernstein EF (2017) Laser tattoo removal. Semin Plast Surg 21:175-192

Bocca B, Sabbioni E, Miceti I, Alimonti A, Petruccia F (2017) Size and metal composition characterization of nano- and microparticles in tattoo inks by a combination of analytical techniques. J Anal Atom Spectrom 3:2616-2628

Boulanger G, Andujar P, Pairon J-C, Billon-Galland M-A, Dion C, Dumortier P, Brochard P, Sobaszek A, Bartsch P, Paris C, Jaurand M-C (2014) Quantification of short and long asbestos fibers to assess asbestos exposure: a review of fiber size toxicity. Environ Health 13:59

Bucella M, Dorigato A, Rizzola F, Caldara M, Fambri L (2018) Influence of the processing parameters on the dispersion and coloration behavior of a halogenated copper phthalocyanine-based masterbatch. Adv Polym Tech 37:21721

CHEM SPACE. https://chem-space.com/

Classification, labelling and packaging regulation (CLP) at ECHA https ://web.archive.org/web/20090309042730/http://echa.europa.eu/ classification/clp_regulation_en.asp

Code of Federal Regulations (2015) Office of the Federal Register; Title 21, Section 703 (f) and 705(b) US Government Printing Office: Washington, DC, 2015

Compiled RAC and SEAC Opinion on an Annex XV dossier proposing restrictions on substances used in tattoo inks and permanent make-up ECHA/RAC/RES-O-0000001412-86-240/F, ECHA/ SEAC/ECHA/SEAC/RES-O-0000001412-86-265/F, https:// echa.europa.eu/it/registry-of-restriction-intentions/-/dislist/detai 1s/0b0236e180dff62a. Accessed April 24th 2020

ECHA substance Infocard. https://echa.europa.eu/substance-informatio $\mathrm{n} /$-/substanceinfo/100.014.125

Everts S (2016) Chemical and Engineering News, American Chemical Society, August 22nd, 2016 FDA cosmetic facts: tattoos and permanent makeup

Gaudron S, Ferrier-Le Bouëdec MC, Franck F, D’Incan M (2014) Azopigments and quinacridones induce delayed hypersensitivity in red tattoos. Contact Dermatitis 72:97-105

Germinario G, van der Werf ID, Sabbatini L (2015) Pyrolysis gas chromatography mass spectrometry of two green phthalocyanine pigments and their identification in paint systems. J Anal Appl Pyrolysis 115:175-183

Giumanini AG, Verardo G, Strazzolini P (1989) The photolysis of 2,4,5,6-tetrachloro-1,3-dicyanobenzene. J Photochem Photobiol A 48:129-153

Golka K, Kopps S, Myslak ZW (2004) Carcinogenicity of azo colorants: influence of solubility and bioavailability. Toxicol Lett 151:203-210

Hauri U (2014) Inks for tattoos and permanent make-up-pigments, preservatives, aromatic amines, polyaromatic hydrocarbons and nitrosamines Swiss National Investigation Campaign 2014 Department of Health, Kanton Basel-Stadt http://www.kantonslab orbsch/dms/kantonslabor/download/berichte/berichte-2014/Tatto o_PMU_2014_EN-UK-/Tattoo_PMU_2014_EN\%28UK\%29pdf

Hauri U, Hohl C (2015) Photostability and breakdown products of pigments currently used in tattoo inks. Curr Probl Dermatol 48:164-169

Herbst W, Hunger K (2004) Industrial organic pigments, 3rd edn. WILEY-VCH Verlag GmbH \& Co, Weinheim
Hering H, Sung AY, Röder N, Hutzler Ch, Berlien HP, Laux P, Luch A, Schreiver I (2018) Laser irradiation of organic tattoo pigments releases carcinogens with 3,3'-dichlorobenzidine inducing DNA strand breaks in human skin cells. J Invest Dermatol 13:2687-2690

Ho SG, Goh CL (2015) Laser tattoo removal: a clinical update. J Cutan Aesthet Surg 8:9-15

Høgsberg T, Loeschner K, Löf D, Serup J (2011) Tattoo inks in general usage contain nanoparticles. Br J Dermatol 165:1210-1218

Kaur RR, Kirby W, Maibach H (2009) Cutaneous allergic reactions to tattoo ink. J Cosmet Dermatol 8:295-300

Kihara R, Imada S, Kawai T, Asahi T (2019) Fabrication of nanorods colloids of copper hexadecafluorophthalocyanine by nanosecond-pulse laser fragmentation in organic solvents. Appl Surf Sci 478:532-538

Klitzman B (2013) Development of permanent but removable tattoos German Federal Institute for Risk Assessment (BfR) conference on tattoo safety; Berlin, Germany; June 6-7, 2013 http://www.bfr. bund.de/cm/343/development-of-permanent-but-removable-tatto os.pdf. Accessed Apr 102019.

Kluger N, Koljonen V (2012) Tattoos, inks, and cancer. Lancet Oncol 13:e161-e168

Koppel DE (1972) Analysis of macromolecular polydispersity in intensity correlation spectroscopy: the method of cumulants. J Chem Phys 57:4814-4820

LaBrosse JL, Anderegg RJ (1984) The mass spectrometer as a chlorineselective chromatographic detector. J Chromatogr A 3:1483-1492

Laumann A, Derick A (2006) Tattoos and body piercings in the United States: a national data set. J Am Acad Dermatol 55:413-421

Laux P, Tralau T, Tentschert J, Blume A, Al Dahouk S, Bäumler W, Bernstein E, Bocca B, Alimonti A, Coleman H, de Cuyper C, Coleb H, Dähne L, Hauri U, Howard PC, Janssen P, Katz L, Klitzman B, Kluger N, Krutak L, Platzek T, Scott-Lang V, Serup J, Teubner W, Schriver I, Wilkniß E, Luch A (2016) A medicaltoxicological view of tattooing. Lancet 387:395-402

Lawson CL, Hanson RJ (1974) Solving least squares problems. Prentice Hall, Englewood Cliffs

Lu F, Wang C, Zhao R, Du L, Fang Z, Guo X, Zhao Z (2018) Review of stratum corneum impedance measurement in non-invasive penetration application. Biosensors 8:31

Ma Y, Guo Y, Wu S, Lv Z, Zhang Q, Ke Y (2017) Titanium dioxide nanoparticles induce size-dependent cytotoxicity and genomic DNA hypomethylation in human respiratory cells. RCS Adv 7:23560-23572

Meng F, Liu X (2014) Growing nano-petals on electrospun micro/nano fibers. RCS Adv 4:8699-8702

Mohanta D, Patnaik S, Sood S, Das N (2019) Carbon nanotubes: evaluation of toxicity at biointerfaces. J Pharm Anal 9:293-300

Muroyama A, Lechler T (2012) Polarity and stratification of the epidermis. Semin Cell Dev Biol 23:890-896

Murphy MJ (2018) High speed ink aggregates are ejected from tattoos during Q-switched Nd:YAG laser treatments. Lasers Surg Med 50:711-717

Pan Z, Lee W, Slutsky L, Clark RAF, Pernodet N, Rafailovich MH (2009) Adverse effects of titanium dioxide nanoparticles on human dermal fibroblasts and how to protect cells. Small 5:511-520

Pothiawala S, Kilmer SL, Ibrahimi OA (2014) Laser tattoo removal. In: Keyvan N (ed) Handbook of lasers in dermatology. Springer, Berlin

Regulations in single European countries: France-Arrêté du 6 mars 2013 fixant la liste des substances qui ne peuvent pas entrer dans la composition des produits de tatouage, https://www.legifrance .gouv.fr/eli/arrete/2013/3/6/AFSP1306308A/jo/texte

Regulations in single European countries: Spain-Información sobre productos para maquillaje permanente (micropigmentación) y 
tatuaje. https://www.aemps.gob.es/informa/notasInformativas/ cosmeticosHigiene/2008/NI-prodAutorizados-tatuaje_julio-2008. htm

Regulations in single European countries: Sweden-Förordning (2012:503) om tatueringsfärger. https://www.riksdagen.se/sv/ dokument-lagar/dokument/svensk-forfattningssamling/forordning -2012503-omtatueringsfarger_sfs-2012-503

Regulations in single European countries: The Netherlands-Besluit van 24 April 2013, houdende wijziging van he Warenwetbesluit tatoeagekleurstoffen in verband met het intrekken van Richtlijn 76/768/EEG. https://zoek.officielebekendmakingen.nl/stb-2013177.html

ResAP (2003) 2 Resolution on tattoos and permanent make-up. https ://search.coe.int/cm/Pages/result_details.aspx?ObjectID $=09000$ 016805df8e5. Accessed Apr 242020

ResAP (2008) 1 Council of Europe Resolution on requirements and criteria for the safety of tattoos and permanent make-up Feb 20th 2008. https://search.coe.int/cm/Pages/result_details.aspx?Objec $\mathrm{tID}=09000016805 \mathrm{~d} 3 \mathrm{dc} 4$. Accessed Apr 242020

Safety Assessment WHO 2002 World Health Organization (WHO) (2002) Folium et Cortex Hamamelidis in "WHO monographs on selected medicinal plants", Geneva: 2:124-136. https://apps.who. int/iris/bitstream/handle/10665/42052/9241545372.pdf?seque nce $=2 \&$ is Allowed $=y$

Safety Assessment (2017) of Hamamelis virginiana (Witch Hazel)derived ingredients as used in cosmetics. https://www.cir-safet y.org/sites/default/files/Witch\%20Hazel.pdf

Schreiver I, Hutzler C, Laux P, Berlien H-P, Luch A (2015) Formation of highly toxic hydrogen cyanide upon ruby laser irradiation of the tattoo pigment phthalocyanine blue. Sci Rep 5:12915

Schreiver I, Hutzler C, Andree S, Laux P, Luch A (2016) Identification and hazard prediction of tattoo pigments by means of pyrolysis-gas chromatography/mass spectrometry. Arch Toxicol 90:1639-1650

Schröder K, Pohlenz-Michel C, Simetska N, Voss J-U, Escher S, Mangelsdorf I (2014) Carcinogenicity and Mutagenicity of Nanoparticles-Assessment of Current Knowledge as Basis for Regulation Fraunhofer Institute for Toxicology and Experimental Medicine, Hannover, On behalf of the Federal Environment Agency (Germany) 50/2014. https://www.umweltbundesamt.de/sites/default/ files/medien/378/publikationen/texte_50_2014_carcinogenicity _and_mutagenicity_of_nanoparticles_1.pdf

Statistics. https://www.advdermatology.com/blog/statistics-surroundin g-tattoo-regret

Steinbach F, Schmidt HH (1975) Metal phthalocyanines used as catalysts in gas phase reactions IV. Oxidation of 2-propanol catalyzed by monomeric beta-Cu-phthalocyanne in the presence of sulfur compounds. J Catal 39:190-197
Swiss Regulation (2005) Das Eidgenössische Departement des Innern (EDI) Verordnung über Gegenstände für den Schleimhaut-, Haut- und Haarkontakt sowie über Kerzen, Streichhölzer, Feuerzeuge und Scherzartikel (Verordnung über Gegenstände für den Humankontakt) Bern: Swiss Government, 2005: 1-26, https:// www.admin.ch/opc/de/classified-compilation/20050181/index .html. Accessed April 24th 2020

TätoV (2008)—Tätowiermittel-Verordnung Nov 13, 2008, BGB1 I S 2215, last amended January 26th, 2016, BGB1 I S 108. https ://www.gesetze-im-internet.de/t_tov/BJNR221500008.html. Accessed Apr 242020

Taylor C, Anderson R, Gange R, Michaud N, Flotte TJ (1991) Light and electron microscopic analysis of tattoos treated by Q-switched ruby laser. J Invest Dermatol 97:131-136

Trouiller B, Reliene R, Westbrook Solaimani AP, Schiestl RH (2009) Titanium dioxide nanoparticles induce DNA damage and genetic instability in vivo in mice. Cancer Res 69:8784-8789

TSCA Inventory March (2020) https://www.epagov/tsca-inventory

Varga Z, Nicol E, Bouchonnet S (2020) Photodegradation of benziosothiazolinone: identification and biological activity of degradation products. Chemosphere 240:124862

Vasold R, Naarmann N, Ulrich H, Fischer D, Konig B, Landthale M, Bäumler W (2004) Tattoo pigments are cleaved by laser light-the chemical analysis in vitro provide evidence for hazardous compounds. Photochem Photobiol 80:185-190

Venugopala Reddy KR, Keshavayya J (2002) Synthesis of symmetrically substituted octabromophthalocyanine pigments and their characterization. Dyes Pigm 53:187-194

Vicum L, Mazzotti M, Iggland M (2019) Precipitation and crystallization of pigments. In: Myerson AS, Lee AY (eds) Handbook of industrial crystallization. Cambridge University Press, Deniz Erdemir

Wang H, Mauthoor S, Din S, Gardener JA, Chang R, Warner M, Aeppli G, McComb DW, Ryan MP, Wu W, Fisher AJ, Stoneham M, Heutz S (2010) Ultralong copper phthalocyanine nanowires with new crystal structure and broad optical absorption. ACS Nano 4:3921-3926

Wang Z, Yang W, Wei J, Meng F, Liu X (2014) Preparation and microwave absorption properties of rod-like iron phthalocyanine with nitrile and nitro groups. Mater Lett 123:6-9

Wenig P, Odermatt J (2010) OpenChrom: a cross-platform open source software for the mass spectrometric analysis of chromatographic data. BMC Bioinform 11:405. http://www.openchrom.net

Publisher's Note Springer Nature remains neutral with regard to jurisdictional claims in published maps and institutional affiliations. 